\title{
THE IAU PROGRAM: EXCHANGE OF ASTRONOMERS
}

\author{
HENNING E. JØRGENSEN \\ Astronomical Observatory \\ Copenhagen University, Denmark
}

The IAU program on Exchange of Astronomers is directed by Commission 38. The details of the program and the way it is carried out are decribed in the IAU Information Bulletins under the heading "Guidelines for Grants". Here I only give some basic facts about the program.

First of all it is a general program. All astronomers can apply and until now Commission 38 has been able to offer a grant to those who fulfill the conditions in the "Guidelines for Grants".

The basic ideas behind the program are simple, namely

- Commission 38 should have funds available for grants to qualified individuals to enable them to visit institutions abroad,

- there must be time and opportunity to interact with the intellectual life of the host institute,

- it is a specific objective that astronomy in the home country be enriched.

Basically three types of candidates may apply. They are faculty/staff members, post-doctoral fellows or graduate students at any recognised educational/research institution or observatory. All candidates must have an excellent record of research.

The main conditions to obtain a grant are that all recipients should return to their home contry after the visit, which must last at least 3 months at a single host institution to give the possibility of a close interaction with colleagues there. However, the IAU's limited budget cannot support both travel and living. It is usually much easier to cover living expenses, due to bilateral agreements between countries, and very cheap living facilities at the host institutes are often available. Therefore the amount of the grant is determined by the cost of one return economy (cheapest) air fare. In special cases the grant can be used for subsistence, if the applicant can cover travel costs.

The visit must formally be agreed to by the Directors of the home and the host institutes with a statement that the applicant returns to his home institute. Due to budget constraints an applicant can only get one grant and IAU cannot pay for accompanying family.

Clearly some sorts of visit are outside the scope of the program. It is not possible to get grants to attend symposia, summer schools, conferences and society meetings and grants will not normally be made for the sole purpose of obtaining observational data. Clearly, travel grants are also not available to take up a position in another place.

31 grants were approved during the triennium 1994-97. The grants went to astronomers in 14 different countries: India (6), Argentina (4), Russia (4), USA (3), Australia (2), China (2), Nigeria (2), Turkey (2), Bulgaria (1), Egypt (1), Israel (1), Japan (1), Morocco (1), Ukraine (1). The host institutes are: USA (12), UK (5), India (4), South Africa (3), Argentina (1), Canada (1), Czech Republic (1), France (1), Spain (1), Sweden (1), Germany (1). The amount available in the IAU budget is: 1992-1994, 76000 CHF; 1995-1997, $88000 \mathrm{CHF}$; 1998-2000, 75000 CHF. According to IAU Information Bulletin No. 80 the actual expenditure was: 1991-1993, 39513 CHF; 1994-1996, $50689 \mathrm{CHF}$

The lower budget for the coming 3 years does not at all indicate a lower priority of the programme, which has the full and enthusiastic support of IAU. The reason is only to give a more realistic budget number but still leave room for increased activity. Also decreasing air fares help a lot. The number of grants per triennium has been relatively stable during a long period with an average of 24 grants. The 31 grants during the last triennium is an indication of increased activity which should continue in the future.

I am often asked if it is difficult to get a grant. The answer is clearly a NO. It is easy and straight forward to get a grant if the "Guidelines for Grants" are fulfilled. And one should notice that our granting program is based on "Guidelines" and not strict rules. Guidelines are always flexible. 